\title{
Reply to letter to editor on "Expectant management of borderline ovarian tumor during pregnancy"
}

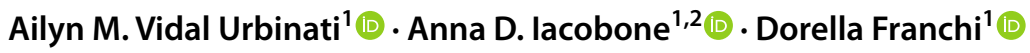 \\ Published online: 7 October 2021 \\ (๑) The Author(s), under exclusive licence to Springer-Verlag GmbH Germany, part of Springer Nature 2021
}

We thank Drs Iavazzo and Gkegkes for their interest in our findings and their comments on our manuscript entitled "Borderline Ovarian Tumor in pregnancy: can surgery wait? A Case Series".

The main goal of our study was to present our experience on the safety of long-term follow-up in borderline ovarian tumors (BOTs) during pregnancy, especially in women with BOT relapse and concomitant pregnancy.

It is important to notice the oncological anamnesis of a pregnant patient presenting with adnexal mass. Despite the experience of the sonographer, it is not easy to discriminate between primary BOT or another type of neoplasia in the absence of previous history of ovarian cancer. Indeed, other tumors may show the same ultrasonographic characteristics of BOT, thus deceiving even an expert ultrasound eye [1].

Therefore, in case of first ultrasound suspicion of BOT during pregnancy, surgical removal of ovarian mass should be performed to confirm histological diagnosis, unless contraindicated because of advanced gestational age [2].

Another advice is not to forget the evaluation of the ovaries in the routine ultrasound during pregnancy, at least up to 20 weeks when visible. If adnexal cyst with solid component has been detected, pregnant women should be immediately referred to expert sonographers and oncologic gynecologists working at tertiary care centers.

This is the comment to the original article available at https://doi. org/10.1007/s00404-021-06080-0.

This reply refers to the comment available online at https://doi.org/ 10.1007/s00404-021-06247-9.

Ailyn M. Vidal Urbinati

ailyn.vidalurbinati@ieo.it

1 Preventive Gynecology Unit, European Institute of Oncology IRCCS, Via Ripamonti 435, 20141 Milan, Italy

2 Department of Biomedical Sciences, University of Sassari, 07100 Sassari, Italy

\section{Declarations}

Conflict of interest The authors declare that they have no conflict of interest.

\section{References}

1. Mascilini F, Savelli L, Scifo MC, Exacoustos C, Timor-Tritsch IE, De Blasis I, Moruzzi MC, Pasciuto T, Scambia G, Valentin L, Testa AC (2017) Ovarian masses with papillary projections diagnosed and removed during pregnancy: ultrasound features and histological diagnosis. Ultrasound Obstet Gynecol 50:116-123. https://doi.org/10.1002/uog.17216

2. Amant F, Berveiller P, Boere IA, Cardonick E, Fruscio R, Fumagalli M, Halaska MJ, Hasenburg A, Johansson ALV, Lambertini M, Lok CAR, Maggen C, Morice P, Peccatori F, Poortmans P, Van Calsteren K, Vandenbroucke T, van Gerwen M, van den HeuvelEibrink M, Zagouri F, Zapardiel I (2019) Gynecologic cancers in pregnancy: guidelines based on a third international consensus meeting. Ann Oncol 30(10):1601-1612. https://doi.org/10.1093/ annonc/mdz228

Publisher's Note Springer Nature remains neutral with regard to jurisdictional claims in published maps and institutional affiliations. 